\title{
Does workplace health promotion contribute to job stress reduction? Three-year findings from Partnering Healthy@Work
}

\author{
Lisa Jarman ${ }^{1}$, Angela Martin², Alison Venn ${ }^{1}$, Petr Otahal ${ }^{1}$ and Kristy Sanderson ${ }^{1 *}$
}

\begin{abstract}
Background: Workplace health promotion (WHP) has been proposed as a preventive intervention for job stress, possibly operating by promoting positive organizational culture or via programs promoting healthy lifestyles. The aim of this study was to investigate whether job stress changed over time in association with the availability of, and/or participation in a comprehensive WHP program (Healthy@Work).

Method: This observational study was conducted in a diverse public sector organization ( 28,000 employees). Using a repeated cross-sectional design with models corroborated using a cohort of repeat responders, self-report survey data were collected via a $40 \%$ employee population random sample in 2010 ( $N=3406)$ and $2013(N=3228)$. Outcomes assessed were effort and reward (self-esteem) components of the effort-reward imbalance (ERI) measure of job stress. Exposures were availability of, and participation in, comprehensive WHP. Linear mixed models and Poisson regression were used, with analyses stratified by sex and weighted for non-response.

Results: Higher WHP availability was positively associated with higher perceived self-esteem among women. Women's mean reward scores increased over time but were not statistically different $(p>0.05)$ after 3 years. For men, higher WHP participation was associated with lower perceived effort. Men's mean ERI increased over time. Results were supported in the cohort group.

Conclusions: For women, comprehensive WHP availability contributed to a sense of organizational support, potentially impacting the esteem component of reward. Men with higher WHP participation also benefitted but gains were modest over time and may have been hindered by other work environment factors.
\end{abstract}

Keywords: Stress, psychological, Workplace, Wellness programs, Health promotions

\section{Background}

Job stress can lead to absenteeism [1] and presenteeism [2], and has been estimated to contribute to $40 \%$ of all job turnover [3]. Evidence favours causal links between job stress and increased risk of down-stream illness [4-7]. The World Health Organisation cites workplace health promotion (WHP) as beneficial to job stress prevention, stating that health-promoting workplaces should address health at a systemic-

\footnotetext{
* Correspondence: Kristy.Sanderson@utas.edu.au

${ }^{1}$ Menzies Institute for Medical Research, University of Tasmania, Private Bag

23, Hobart 7000, TAS, Australia

Full list of author information is available at the end of the article
}

(policies, practices, systems) as well as individual-level [8]. However, findings in favour of effective systemslevel intervention to prevent job stress remain inconclusive $[9,10]$. Evidence for stress prevention largely stems from individual-level stress management interventions [9-12].

Comprehensive WHP, a term given to interventions targeting both individual- and system-levels [13], has proven popular among employers, with associated decreases in absenteeism, presenteeism [14] and financial returns on investment $[15,16]$. Nevertheless, publications citing research on comprehensive forms of WHP 
with job stress outcomes are uncommon [17] with the majority focusing on employee participation [18].

Conceptually, WHP appears associated with job stress in two key ways. First, investment in the 'social capital' of the organisation [19-21] may contribute to workers' perceptions of support [19] from their organisation because the employer shows care for their health and wellbeing $[22,23]$. The presence of WHP may also serve to reduce the stigma associated with reporting health-related issues or to enhance general health awareness among employees [23]. These emotional and cognitive effects have been linked to improved job satisfaction $[18,24]$ and mental health [25]. However, we were unable to identify any published articles that separated WHP availability from WHP participation when assessing whole-ofworkforce job stress.

Second, exposure to job stress can provoke short-term behavioural responses such as inappropriate nutrition [26], smoking [27], physical inactivity [28] and alcohol consumption [29]. Extended exposure to situations stimulating stress responses can also lead to chronic arousal or strain [30]. Participation in workplace activities targeting known health risks or enhancing work-related coping strategies aims to reduce job stress. Meta-analytic research supports this link between participation in WHP programs, reduced job stress and improved mental health $[9,10,18,31]$. Comprehensive strategies have also been shown to be more effective than approaches tackling only organisational or individual-level factors [32]. However, gaps remain in understanding time-related effects [17] and intervention effectiveness when WHP is scaled-up in size to intervene with whole working populations [33].

Effort-reward imbalance (ERI) concepts appear suited to assessing both pathways and a strong evidence-base is available across a broad range of occupations supporting the association between self-reported measures of ERI and enduring health outcomes such as cardiovascular disease $[34,35]$ and diabetes [36]. Effort-reward imbalance theory asserts that work is a form of mutual exchange, or reciprocity, where job-related efforts are traded for rewards (i.e., job security, career advancement, self-esteem) as a type of 'social contract'. The theory proposes that insufficient reward for work effort can negatively impact upon the capacity of an individual to regulate their emotions, thoughts and behaviours, which in turn can lead to job strain [37]. Workplace health promotion may be viewed as an organisational benefit signaling regard for an employee's welfare, thereby increasing perceived organisational support and enhancing self-esteem [19]. Research has highlighted that ERI measures explain unique variance in relation to the macro- or contractual factors contributing to mental health outcomes, and that the effort dimension can be likened to jobrelated demands [38, 39].
This project evolved from a collaboration between university researchers and government (public sector) that had the goal of evaluating the long-term effectiveness of a comprehensive multi-component WHP initiative, named Healthy@Work. Baseline workforce survey data had indicated that ERI was a key correlate of high psychological distress among employees, and that mental health varied by sex when compared with working population norms [40]. We hypothesized that i) higher availability of WHP would be positively associated with perceived reward, particularly through improved selfesteem (given job security and career progression were unlikely to be impacted by WHP), and ii) higher participation in WHP would be negatively associated with perceived effort.

\section{Methods}

\section{Setting and study population}

Tasmania is an Australian region with a population of around half a million people. The Tasmanian Government employed approximately 28,000 public sector workers across 14 separate organizations (government departments), which are highly diverse in their functions (e.g., health, education, fire services), locations (e.g., urban, rural, remote) and occupations. Participants were drawn from this working population and gave informed consent for study involvement, including publication. Ethics approval for the study was obtained from the Human Research Ethics Committee (Tasmania) Network (ID: H0010501).

\section{Intervention}

Overview

Between 2009 and 2012, the Tasmanian Government invested approximately $\$ 2$ million in a whole-ofworkforce WHP intervention called Healthy@Work. A small, centralised Healthy@Work team was responsible for the associated structural changes including strategy, model development, principles and implementation cycle, and was tasked with oversight of this new government policy focus on WHP. Implementation was mandatory and was delegated to the senior executive of each government department. It was internally audited each year until its conclusion in mid-2012. Our research team commenced a partnership with the Tasmanian Government in 2010 to conduct a naturalistic evaluation of the intervention.

\section{Department-based activities}

Departments were responsible for establishing in-house WHP vision, strategies and action plans, and for reporting on progress. Grant funding was available to departments as an incentive for WHP including for example, development of a workplace health promotion resource 
toolkit, funding equipment or recreation spaces, development of a computer-based system to interrupt sitting time and prompt healthy activity, and individual assessment, activity or education programs. The number of departments with an established WHP program increased from 6 in 2009 to 13 in 2012. The mean number of initiatives per department increased from 13 in 2009 to 48 in 2012 (Additional file 1: Figure S1).

\section{Exposures}

Healthy@Work strategies targeted i) individuals via mental health and well-being, health education, health assessments, physical activity, and injury management, and ii) organizational change through initiatives such as increasing physical space for health-activities, making healthy food options available, funding onsite gymnasiums, giving access to stairs, promoting health via information bulletins and implementing healthpromoting policies. Primary job stress prevention strategies (e.g., job control) were not included in Healthy@Work.

For analysis of individual exposures we first calculated a score indicating the 'availability' of Healthy@Work strategies [41]. This score was obtained from questions asking respondents to provide a 'yes' or 'no' answer to a specified list of Healthy@Work amenities and programs (Additional file 2: Figure S2). The availability timeframe was 'the previous 12 months' in 2010 as a baseline reference period and 'the previous 3 years' in 2013 to capture the period over which Healthy@Work was implemented. A 'total availability' score was derived from per-person counts of positive responses to question items and a minimum score of 1 was needed to calculate participation. This approach was taken so that respondents could distinguish between work situations were WHP interventions were available (including health-promoting environments), and where they actually participated in activities. Where participants provided a 'yes' answer to activities, they were asked for the number of times they had participated and we used this information to calculate a total participation score per person (Additional file 2: Figure S2 describes calculations).

\section{Outcomes}

Our overall measure of job stress outcome was Effortreward imbalance (ERI). We applied the 17 item ERI questionnaire, which is a validated self-report survey with 6 items measuring Effort and 11 items dedicated to Reward [42]. A ratio is typically calculated for every person by first adding all scores for each of the effort $(e)$ and reward $(r)$ scales, then applying the formula $e /(r \times c)$ where $c$ equals the proportion 6/11. Scores $\geq 1$ are argued to indicate job strain conditions. The procedure for calculating the Reward component and its subscales of self-esteem, job security and career advancement has been described elsewhere [42]. Continuous scale scores were used to maximize the data available for analysis.

\section{Participants and sample size}

We collected data via repeated, cross-sectional postal survey (2010 and 2013), selecting a $40 \%$ random population sample from the total pool of workers, stratified according to employment condition, employment category and department (Additional file 3: Figure S3). In 2013 a portion of workers were re-selected by chance and survey respondents from this group were referred to as the 'cohort' (men $=161$; women $=423$ ). Survey responses were merged with de-identified administrative data and this process enabled propensity weighting to adjust for possible non-response bias (described below).

\section{Statistical analysis and methods}

The repeated cross-sectional surveys were analyzed together in two-stages: 1) assessing whether mean ERI or its subcomponent scores changed over time and estimating associations between these scores and the availability of, or participation in Healthy@Work programs in 2010 and 2013; and 2) assessing whether there were changes in availability or participation over time. Survey responses were anticipated to be more similar within government departments, and for those who were in the cohort of repeat respondents. Mixed-effects linear regression modelling with random intercepts for department and participants was used to allow for correlated responses. Models were stratified by sex due to known differences in employee reporting of psychological distress. In stage 1, linear mixed-models were constructed with the outcome ERI (or its subcomponents) and a dummy variable for 'survey year' in the fixed effect section of each model along with covariates for confounders [43]. This process allowed us to determine whether ERI scores or their components changed by survey year. We then added covariates for total availability or participation. We tested for interaction between survey year and Healthy@Work exposure variables in each model to assess whether the effect of exposure changed between surveys. Confounders were identified via regression modelling techniques described by Hosmer, Lemeshow and Sturdivant [44] and were defined as those variables that were associated with the outcome and which also produced more than $10 \%$ change in an estimated coefficient of the model.

Poisson regression with random effects as above was used to assess whether mean availability of, or participation in Healthy@Work strategies had changed over time. 
Model diagnostics from linear mixed effects models showed that residuals were skewed and an inverse transformation was applied to the ERI values. We then back-transformed the ERI results to present mean estimates on the original scale of measurement. Further we applied propensity weighting as described by Little and Rubin [45] to deal with potential nonresponse bias; the propensity model included age, sex, government department, employment category, employment condition, and tenure using the human resources administrative database as the reference population.

Models showing relationships between the exposure and outcome were corroborated by replicating the analysis with the repeat-respondent cohort. All analyses were conducted using STATA 12.1 (StataCorp LP, Texas, USA).

\section{Results}

\section{Participants}

Survey response proportions were $28 \%(n=3406)$ in 2010 and $27 \%(n=3228)$ in 2013 . When compared with nonresponders, responders tended to be older, have longer average tenure, and for women, be permanent employees (Additional file 4: Table S1). Weighting addressed these response variations. Table 1 shows basic respondent characteristics across both time-points. Men were proportionally more likely to be full-time employed ( $84 \%$ in 2013) than women (48 \% in 2013).

The cohort group had some distinguishing features from the general respondent group (Additional file 5: Table S2) with men working longer hours, having higher average education, slightly more permanency of employment and higher average tenure overall. Women in the

Table 1 Respondent characteristics for the 2010 and 2013 Partnering Healthy@Work workforce surveys

\begin{tabular}{|c|c|c|c|c|c|c|c|c|c|c|}
\hline \multirow[b]{3}{*}{ Continuous Variables } & \multicolumn{4}{|l|}{ Men } & \multirow[b]{3}{*}{$p$} & \multicolumn{4}{|c|}{ Women } & \multirow[b]{3}{*}{$p$} \\
\hline & \multicolumn{2}{|l|}{2010} & \multicolumn{2}{|l|}{2013} & & \multicolumn{2}{|l|}{2010} & \multicolumn{2}{|l|}{2013} & \\
\hline & Mean & SD & Mean & SD & & Mean & SD & Mean & SD & \\
\hline Age [years, mean] (SE) & 47.1 & 10.1 & 47.6 & 10.4 & 0.212 & 45.8 & 10.4 & 46.8 & 10.3 & 0.001 \\
\hline Tenure (SE) & 14.1 & 11.8 & 14.9 & 11.7 & 0.125 & 12.7 & 10.2 & 13.0 & 10.3 & 0.211 \\
\hline Hours worked (SE) & 40.4 & 12.9 & 40.1 & 13.4 & 0.667 & 36.8 & 15.7 & 36.0 & 15.6 & 0.078 \\
\hline Annual Salary $(\$ A U)^{a}$ & 66,566 & 20,487 & 73,608 & 36,033 & $<0.001$ & 63,232 & 20,073 & 70,091 & 20,333 & $<0.001$ \\
\hline Categorical Variables & $\%$ & $\mathrm{n}$ & $\%$ & $\mathrm{n}$ & & $\%$ & $\mathrm{n}$ & $\%$ & $n$ & \\
\hline \multicolumn{11}{|l|}{ Marital Status } \\
\hline Married/ Partner & 91 & 774 & 94 & 763 & ref & 85 & 1767 & 85 & 1711 & ref \\
\hline Not married & 9 & 79 & 6 & 52 & 0.029 & 15 & 313 & 15 & 301 & 0.937 \\
\hline \multicolumn{11}{|l|}{ Education } \\
\hline Post school & 61 & 495 & 66 & 514 & ref & 68 & 1308 & 66 & 1239 & ref \\
\hline Middle school & 3 & 23 & 2 & 12 & 0.053 & 2 & 40 & 2 & 36 & 0.826 \\
\hline Upper school & 36 & 291 & 32 & 248 & 0.064 & 30 & 567 & 32 & 606 & 0.087 \\
\hline \multicolumn{11}{|l|}{ Employment band } \\
\hline Low/mid band & 75 & 719 & 78 & 716 & ref & 89 & 2183 & 94 & 2166 & Ref \\
\hline High/very high band & 25 & 245 & 22 & 200 & 0.068 & 11 & 261 & 6 & 145 & $<0.001$ \\
\hline \multicolumn{11}{|l|}{ Employment Category } \\
\hline Employment Category & 88 & 848 & 86 & 785 & ref & 92 & 2256 & 88 & 2034 & ref \\
\hline Fixed-term/ casual & 12 & 116 & 14 & 131 & 0.146 & 8 & 188 & 12 & 276 & $<0.001$ \\
\hline \multicolumn{11}{|l|}{ Employment Condition } \\
\hline Full-time & 84 & 814 & 84 & 772 & ref & 51 & 1243 & 48 & 1105 & ref \\
\hline Part-time & 16 & 150 & 16 & 144 & 0.924 & 49 & 1201 & 52 & 1206 & 0.036 \\
\hline \multicolumn{11}{|l|}{ Days worked } \\
\hline Mon to Fri & 69 & 665 & 75 & 646 & ref & 53 & 1289 & 63 & 1205 & ref \\
\hline Days Vary Weekly & 18 & 170 & 19 & 160 & 0.796 & 16 & 382 & 19 & 367 & 0.739 \\
\hline Other & 13 & 122 & 6 & 55 & $<0.001$ & 31 & 759 & 18 & 355 & $<0.001$ \\
\hline Total Respondents & & 964 & & 917 & & & 2444 & & 2311 & \\
\hline
\end{tabular}


cohort also had higher tenure, higher average age and were more likely to be in permanent positions.

\section{Availability of and participation in workplace health promotion}

Estimated percentages of workers reporting availability of different types of Healthy@Work initiatives in 2010 and 2013 are illustrated in Fig. 1. Poisson modelling (Additional file 6: Table S3) showed that WHP availability was 14\% higher (for men and women) in 2013 (95\% CI: $12 \%$ to $17 \%)$. The number of times men and women participated across all programs had approximately doubled in 2013.

\section{Univariable correlates of effort reward imbalance}

Covariates univariably associated with ERI were age, marital status, annual salary, education, employment band, employment category, employment condition, tenure, hours worked and regular work-days (Table 2). In subsequent model testing, age was a confounder for availability and age and employment band were confounders for participation among men. However the models presented here were only adjusted for age so as to standardize comparisons across all models and maximize discussion across the whole employee group. Had the models all been adjusted for employment condition, description would have been narrowed to reference the higher-band employee group.

\section{Repeated cross-sectional modelling} Changes in effort reward imbalance over time

Table 3 shows that men's ERI score estimates excluding exposure to WHP were approximately 4 points higher over time $(p<0.001)$, with corresponding increases in perceived effort and decreases in perceived reward, including its subcomponents of self-esteem, job security and career promotion. These results indicate there were basic increases in ERI scores for men in 2013 (i.e., timebased differences) that were not accounted for by the socio-demographic factors or work characteristics measured here. Women's results indicate mean ERI scores were less over time, but were not statistically different between 2010 and $2013(p=0.414)$.

\section{Changes in perceived effort and reward in association with WHP}

At baseline, Table 3 also shows an inverse and additive relationship was identified between higher participation in WHP and lower effort scores for men $[\beta=-0.024$, $95 \%$ CI: -0.036 to -0.012$]$. Over time the magnitude of effect for this association increased $(p=<0.001)$ but estimated beta-values were modest overall. Sub-analysis of this model (not shown) adjusting for employment band and age was slightly more conservative $[ß=-0.025,95 \% \mathrm{CI}$ : -0.043 to $-0.007(p=0.009)]$. Statistical associations

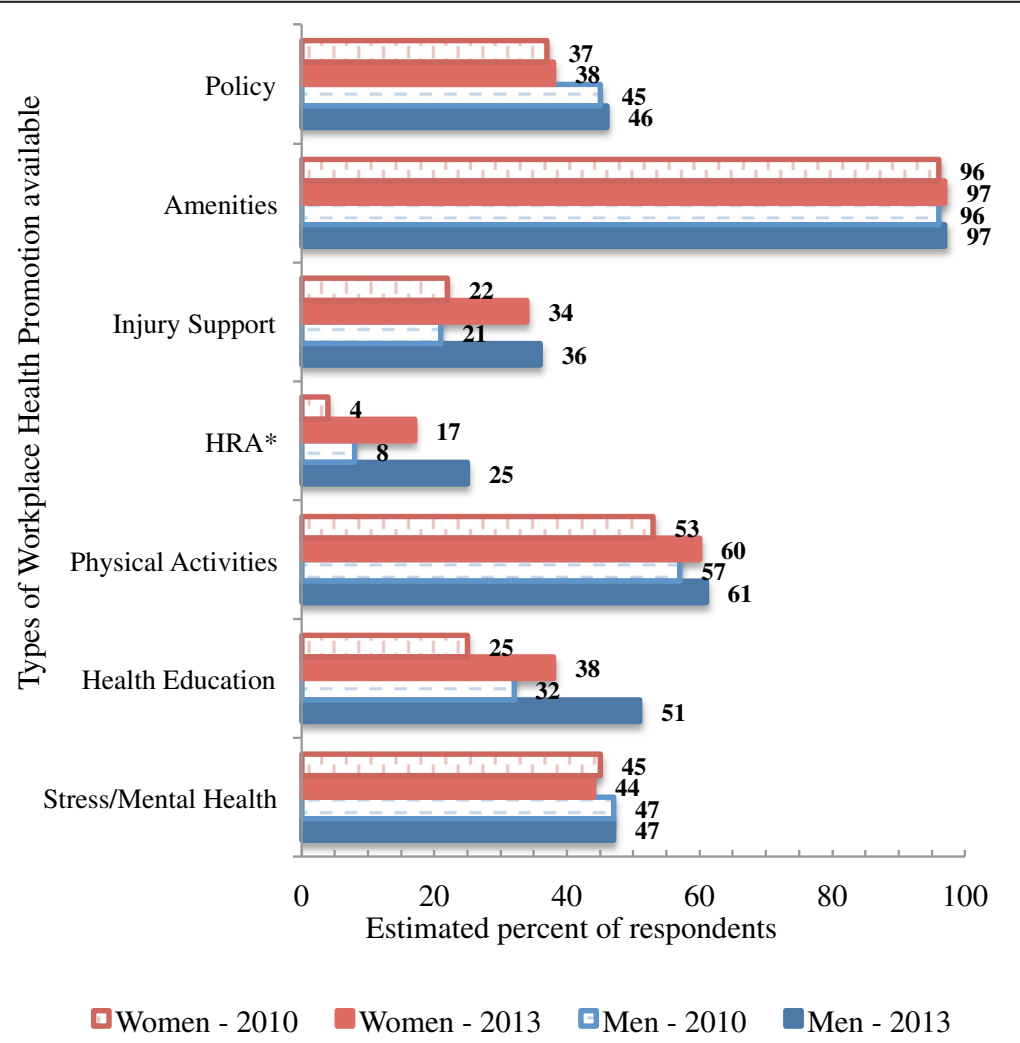

Fig. 1 The range of available Healthy@Work initiatives in 2010 and 2013 reported by respondents in 2010 and 2013 
Table 2 Univariable associations between Effort-Reward Imbalance and respondent characteristics stratified by sex and survey year

\begin{tabular}{|c|c|c|c|c|c|c|c|c|c|c|c|c|}
\hline \multirow{4}{*}{$\frac{\text { Effort-Reward Imbalance }}{\text { Age (continuous) }}$} & \multicolumn{6}{|l|}{ Men } & \multicolumn{6}{|l|}{ Women } \\
\hline & \multicolumn{3}{|l|}{2013} & \multicolumn{3}{|l|}{2010} & \multicolumn{3}{|l|}{2013} & \multicolumn{3}{|l|}{2010} \\
\hline & \multirow{2}{*}{$\begin{array}{l}\beta \\
0.001\end{array}$} & \multicolumn{2}{|l|}{$95 \% \mathrm{Cl}$} & \multirow{2}{*}{$\begin{array}{l}B \\
-0.001\end{array}$} & \multicolumn{2}{|l|}{$95 \% \mathrm{Cl}$} & \multirow{2}{*}{$\begin{array}{l}B \\
0.000\end{array}$} & \multicolumn{2}{|l|}{$95 \% \mathrm{Cl}$} & \multirow{2}{*}{$\begin{array}{l}B \\
0.001\end{array}$} & \multicolumn{2}{|l|}{$95 \% \mathrm{Cl}$} \\
\hline & & -0.001 & 0.001 & & -0.002 & 0.000 & & -0.001 & 0.001 & & 0.000 & 0.001 \\
\hline \multicolumn{13}{|l|}{ Marital status } \\
\hline Married/Partner & ref & & & ref & & & ref & & & ref & & \\
\hline Not married & 0.013 & -0.047 & 0.072 & -0.026 & -0.051 & -0.051 & 0.012 & -0.007 & 0.032 & 0.013 & -0.007 & 0.033 \\
\hline Annual salary & 0.011 & -0.003 & 0.003 & 0.002 & -0.005 & 0.010 & 0.010 & 0.002 & 0.019 & 0.011 & 0.000 & 0.022 \\
\hline \multicolumn{13}{|l|}{ Education } \\
\hline Post school & ref & & & ref & & & ref & & & ref & & \\
\hline School & -0.023 & -0.020 & 0.032 & -0.020 & -0.040 & 0.000 & -0.030 & -0.046 & -0.014 & -0.023 & -0.038 & -0.008 \\
\hline \multicolumn{13}{|l|}{ Band } \\
\hline Low/mid & ref & & & ref & & & ref & & & ref & & \\
\hline High/very high & 0.039 & -0.023 & 0.024 & 0.024 & 0.003 & 0.003 & 0.020 & -0.003 & 0.043 & 0.039 & 0.019 & 0.059 \\
\hline \multicolumn{13}{|l|}{ Employment category } \\
\hline Permanent & ref & & & ref & & & ref & & & ref & & \\
\hline Fixed term/casual & -0.026 & -0.089 & -0.033 & -0.028 & -0.056 & -0.001 & -0.034 & -0.053 & -0.015 & -0.026 & -0.048 & -0.003 \\
\hline \multicolumn{13}{|l|}{ Employment condition } \\
\hline Full-time & ref & & & ref & & & ref & & & ref & & \\
\hline Part-time & -0.029 & -0.058 & -0.006 & -0.030 & -0.055 & -0.005 & -0.035 & -0.048 & -0.022 & -0.029 & -0.041 & -0.017 \\
\hline Tenure & 0.002 & -0.001 & 0.001 & 0.001 & 0.000 & 0.002 & 0.001 & 0.001 & 0.002 & 0.002 & 0.002 & 0.003 \\
\hline \multicolumn{13}{|l|}{ Regular day worked } \\
\hline Yes & ref & & & ref & & & ref & & & ref & & \\
\hline No & -0.032 & -0.058 & -0.006 & -0.028 & -0.049 & -0.008 & -0.040 & -0.058 & -0.022 & -0.032 & -0.048 & -0.017 \\
\hline Hours worked (continuous) & 0.002 & 0.001 & 0.003 & 0.003 & 0.002 & 0.003 & 0.002 & 0.002 & 0.002 & 0.002 & 0.002 & 0.002 \\
\hline
\end{tabular}

between WHP availability and reward (and its subcomponent self-esteem) were neither present at baseline nor over time for men $(p=0.218)$. Similar results were also found for the reward sub-component, self-esteem $(p=0.827)$ for this group.

For women, no statistical relationship was identified between WHP participation and effort at either time point $(p=0.420)$. However an additive association was found at baseline between higher WHP availability and higher perceived reward [ $\beta=0.161,95 \% \mathrm{CI}: 0.029$ to 0.293] that included higher self-esteem for this group. Over time the magnitudes of effect for these associations both increased (reward: $p=0.020$; self-esteem: $p<0.001$ ) among women but did not translate to a statistical difference in either reward or self-esteem in 2013.

\section{Cohort analyses}

To corroborate the effects observed in repeated crosssectional analyses we replicated our models using confirmatory evidence from the cohort of repeat responders (Table 4). The model results show a high degree of overlap for coefficient estimates of the cohort and general respondent populations. However, for the model regressing job security on WHP availability, the strength of association changed over time $(p=0.065)$ for the cohort group but not within the whole respondent population $(p=0.135)$.

\section{Discussion}

Our first hypothesis, that higher availability of WHP would be positively associated with perceived reward through improved self-esteem was supported among women but not men. Our second hypothesis, that higher participation in WHP would be negatively associated with perceived effort was supported for men but not women. However, the magnitudes of effect for these additive associations were modest and were not reflected as statistical differences in perceived effort or reward (including self-esteem) at a working-population level over time. We found a high corroboration between results for the repeat-responder cohort and the broader respondent group, which was randomly sampled and weighted to minimize non-response bias. Therefore these results seem generalizable to the source population of public sector workers under study. 
Table 3 Linear mixed models for all respondents regressing Effort Reward Imbalance on Workplace Health Promotion ${ }^{e}$ exposures

\begin{tabular}{|c|c|c|c|c|c|c|c|c|c|c|c|c|c|c|}
\hline \multirow{4}{*}{$\frac{\text { Outcome measure }}{\text { ERI (mean) }}$} & \multicolumn{6}{|l|}{ Men } & \multirow{4}{*}{$\frac{p^{\mathrm{b}}}{<0.001}$} & \multicolumn{6}{|l|}{ Women } & \multirow{4}{*}{$\frac{p}{0.414}$} \\
\hline & \multicolumn{3}{|l|}{2010} & \multicolumn{3}{|l|}{2013} & & \multicolumn{3}{|l|}{2010} & \multicolumn{3}{|l|}{2013} & \\
\hline & \multirow{2}{*}{$\begin{array}{l}\beta^{a} \\
0.371\end{array}$} & \multicolumn{2}{|l|}{$95 \% \mathrm{Cl}$} & \multirow{2}{*}{$\begin{array}{l}\beta \\
0.410\end{array}$} & \multicolumn{2}{|l|}{$95 \% \mathrm{Cl}$} & & \multirow{2}{*}{$\frac{\beta^{a}}{0.373}$} & \multicolumn{2}{|l|}{$95 \% \mathrm{Cl}$} & \multirow{2}{*}{$\begin{array}{l}\beta \\
0.366\end{array}$} & \multicolumn{2}{|l|}{$95 \% \mathrm{Cl}$} & \\
\hline & & 0.351 & 0.351 & & 0.384 & 0.435 & & & 0.357 & 0.357 & & 0.344 & 0.387 & \\
\hline Reward & 47.88 & 45.63 & 50.13 & 44.97 & 42.28 & 42.28 & $<0.001$ & 47.41 & 46.71 & 48.10 & 47.73 & 47.19 & 48.26 & 0.267 \\
\hline Self-esteem & 21.95 & 21.26 & 22.64 & 21.10 & 20.29 & 21.90 & 0.002 & 21.65 & 21.20 & 22.10 & 21.65 & 21.32 & 21.98 & 0.897 \\
\hline Job security & 8.77 & 7.84 & 9.70 & 7.12 & 6.09 & 8.14 & $<0.001$ & 8.39 & 8.22 & 8.55 & 8.26 & 7.88 & 8.63 & 0.488 \\
\hline Career promotion & 16.32 & 14.96 & 17.69 & 15.10 & 13.66 & 16.54 & $<0.001$ & 16.36 & 15.96 & 16.76 & 16.68 & 16.34 & 17.01 & 0.010 \\
\hline Effort & 10.13 & 9.69 & 10.56 & 10.80 & 10.40 & 11.21 & $<0.001$ & 9.99 & 9.60 & 10.38 & 9.85 & 9.31 & 10.38 & 0.494 \\
\hline Exposure & $\beta^{c}$ & $95 \% \mathrm{Cl}$ & & $\beta$ & $95 \% \mathrm{Cl}$ & & p & $\beta^{c}$ & $95 \% \mathrm{Cl}$ & & $\beta$ & $95 \% \mathrm{Cl}$ & & p \\
\hline WHP Availability & \multicolumn{3}{|c|}{$(\sim n=947)$} & \multicolumn{3}{|c|}{$(\sim n=906)$} & & \multicolumn{3}{|c|}{$(\sim n=2396)$} & \multicolumn{3}{|c|}{$(\sim n=2283)$} & \\
\hline ERI & -0.006 & -0.011 & -0.001 & -0.008 & -0.013 & -0.002 & 0.008 & -0.003 & -0.001 & 0.003 & -0.004 & -0.007 & -0.002 & $0.002^{d}$ \\
\hline Reward & 0.332 & -0.185 & 0.848 & 0.295 & -0.156 & -0.156 & 0.218 & 0.161 & 0.029 & 0.293 & 0.154 & 0.020 & 0.288 & 0.020 \\
\hline Self-esteem & 0.040 & -0.317 & 0.397 & 0.037 & -0.295 & 0.369 & 0.827 & 0.135 & 0.062 & 0.207 & 0.128 & 0.050 & 0.206 & $<0.001$ \\
\hline Job security & 0.059 & -0.018 & 0.136 & 0.148 & 0.012 & 0.283 & $0.043^{d}$ & -0.042 & -0.096 & 0.012 & -0.035 & -0.090 & 0.019 & 0.135 \\
\hline Career promotion & 0.088 & -0.034 & 0.211 & 0.076 & -0.026 & 0.178 & 0.167 & 0.027 & -0.080 & 0.134 & 0.026 & -0.087 & -0.087 & 0.627 \\
\hline WHP Participation & \multicolumn{3}{|c|}{$(\sim n=735)$} & \multicolumn{3}{|c|}{$(\sim n=759)$} & & \multicolumn{3}{|c|}{$(\sim n=1804)$} & \multicolumn{3}{|c|}{$(\sim n=1881)$} & \\
\hline Effort & -0.024 & -0.036 & -0.012 & -0.023 & -0.035 & -0.012 & $<0.001$ & 0.011 & -0.015 & 0.036 & 0.011 & -0.013 & 0.034 & 0.420 \\
\hline
\end{tabular}

aEstimated scale score excluding exposure after back-transformation and controlling for confounders

${ }^{b} p$-value of linear mixed models regressing the outcome measure on survey year. Models were adjusted for age

'Values represent the results from linear mixed models including exposure variable. Beta values have been back-transformed to estimate the coefficient on the original scale

${ }^{\mathrm{d}}$ Represents interaction term present in model

'The results are based on a composite measure that includes all forms of workplace health promotion [WHP] (i.e., policy, amenities, injury support, health risk assessment, physical activities, health education, stress/mental health)

To show effects at a population level, additive relationships rely on increased dosage of exposure (e.g., higher volumes of availability or higher participation levels). In 2013 self-reported WHP availability increased by $14 \%$ and participation approximately doubled over time. Systematic differences in occupational exposures between sexes, linked to disparities in perceptions and/or reporting and variations in exposure between or within jobs [46] may also have contributed to our results. Recently published results from this project have indicated that where activities were available, participation was less likely among employees with cardio-metabolic conditions, those who smoked and workers with variable work schedules. Participation was more likely among administrative staff and those who participated in leisure time physical activity [47].

For women, we infer WHP availability contributed to perceptions of organisational support thereby enhancing self-esteem [20]. The ERI self-esteem construct was derived from items capturing perceptions of i) respect from supervisors and colleagues, ii) adequacy of support in difficult situations, and iii) effects of job interruptions [42]. Research using this concept of social exchange for other forms of non-monetary employee benefits, such as manager trustworthiness and procedural justice has supported their relationship with job satisfaction and employee turnover [48]. However, the increases in WHP availability may have been of insufficient dose, or may have needed supplement from other non-monetary benefits to show changes in self-esteem at a population-level. A study of Chinese physicians, by Li and colleagues [49] has found differences in the way men and women perceive the reward sub-factor of ERI when facing similar work environments.

The time period for Healthy@Work implementation coincided with the global economic downturn, which had major financial ramifications for the Tasmanian Government. During the implementation period, government directives also focused on long-term reduction of operating costs, including labor costs via vacancy control and productivity management. For men, who were higher wage-earners and more likely to be working in full-time or management positions, it is possible that the adverse events reported here may have contributed to perceived or real threats of job-loss and work intensification at population-level [50]. Higher WHP participation may have enhanced work-related coping or personal well-being but it was only one side of the effort-reward equation. We interpret that men did not perceive WHP availability as a reward. It is possible that men in this workforce were more sensitive to job security than socio-emotional relationship issues [51]. We note that sex-based differences in occupational exposures been 
Table 4 Linear mixed models for the cohort group regressing Effort Reward Imbalance on Workplace Health Promotion ${ }^{e}$ exposures

\begin{tabular}{|c|c|c|c|c|c|c|c|c|c|c|c|c|c|c|}
\hline \multirow{4}{*}{$\frac{\text { Outcome measure }}{\mathrm{ERI} \text { (mean) }}$} & \multicolumn{7}{|c|}{ Men $(n=161)$} & \multicolumn{7}{|c|}{ Women $(n=423)$} \\
\hline & \multicolumn{3}{|l|}{2010} & \multicolumn{4}{|l|}{2013} & \multicolumn{3}{|l|}{2010} & \multicolumn{4}{|l|}{2013} \\
\hline & \multirow{2}{*}{$\begin{array}{l}\beta^{\mathrm{a}} \\
0.379\end{array}$} & \multicolumn{2}{|l|}{$95 \% \mathrm{Cl}$} & \multirow{2}{*}{$\begin{array}{l} \\
0.422\end{array}$} & \multicolumn{2}{|l|}{$95 \% \mathrm{Cl}$} & \multirow{2}{*}{$\frac{p^{b}}{<0.001}$} & \multirow{2}{*}{$\frac{\beta}{0.376}$} & \multicolumn{2}{|l|}{$95 \% \mathrm{Cl}$} & \multirow{2}{*}{$\begin{array}{l}\beta \\
0.369\end{array}$} & \multicolumn{2}{|l|}{$95 \% \mathrm{Cl}$} & \multirow{2}{*}{$\frac{p^{\mathrm{b}}}{0.496}$} \\
\hline & & 0.353 & 0.404 & & 0.389 & 0.457 & & & 0.342 & 0.411 & & 0.330 & 0.408 & \\
\hline Reward & 49.47 & 47.98 & 50.96 & 46.42 & 46.42 & 48.58 & 0.012 & 45.62 & 40.27 & 50.96 & 45.93 & 40.61 & 51.26 & 0.237 \\
\hline Self-esteem & 22.54 & 21.98 & 23.07 & 21.73 & 20.99 & 22.48 & 0.010 & 20.78 & 17.90 & 23.67 & 20.80 & 18.06 & 23.53 & 0.961 \\
\hline Job security & 9.26 & 8.05 & 10.48 & 7.12 & 6.16 & 8.07 & $<0.001$ & 7.67 & 6.21 & 9.13 & 7.61 & 5.98 & 9.24 & 0.851 \\
\hline Career promotion & 17.50 & 16.69 & 16.69 & 16.26 & 15.15 & 17.37 & 0.004 & 16.47 & 15.34 & 15.34 & 16.81 & 15.95 & 17.68 & 0.012 \\
\hline Effort & 10.42 & 9.74 & 11.11 & 11.18 & 10.47 & 11.90 & 0.020 & 0.020 & 9.46 & 11.00 & 10.09 & 9.21 & 10.96 & 0.577 \\
\hline Exposure & $\beta^{c}$ & $95 \% \mathrm{Cl}$ & & $\beta$ & $95 \% \mathrm{Cl}$ & & $p$ & $\beta$ & $95 \% \mathrm{Cl}$ & & $\beta$ & $95 \% \mathrm{Cl}$ & & $p$ \\
\hline \multicolumn{15}{|l|}{ WHP Availability } \\
\hline ERI & -0.006 & -0.012 & -0.001 & -0.008 & -0.014 & -0.001 & 0.012 & 0.001 & -0.001 & 0.003 & -0.004 & -0.007 & -0.001 & $0.002^{\circ}$ \\
\hline Reward & 0.338 & -0.235 & 0.911 & 0.301 & -0.201 & 0.802 & 0.251 & 0.124 & 0.006 & 0.242 & 0.118 & 0.004 & 0.239 & 0.072 \\
\hline Self-esteem & 0.041 & -0.339 & 0.421 & 0.038 & -0.318 & 0.395 & 0.395 & 0.102 & 0.024 & 0.180 & 0.128 & 0.050 & 0.206 & 0.022 \\
\hline Job security & 0.055 & -0.042 & 0.151 & 0.131 & -0.006 & 0.278 & $0.091^{d}$ & -0.044 & -0.092 & 0.006 & -0.033 & -0.081 & 0.014 & 0.065 \\
\hline Career promotion & 0.104 & -0.043 & 0.252 & 0.091 & -0.033 & 0.215 & 0.173 & 0.023 & -0.086 & 0.132 & 0.024 & -0.092 & 0.140 & 0.684 \\
\hline \multicolumn{15}{|l|}{ WHP Participation } \\
\hline Effort & -0.037 & -0.064 & -0.011 & -0.036 & -0.062 & -0.011 & 0.003 & 0.014 & -0.016 & 0.043 & 0.015 & -0.016 & 0.046 & 0.117 \\
\hline
\end{tabular}

${ }^{a}$ Estimated scale score excluding exposure after back-transformation and controlling for confounders

${ }^{\mathrm{b}} p$-value of linear mixed models regressing the outcome measure on survey year. Models were adjusted for age

'Values represent the results from linear mixed models including exposure variable. Beta values have been back-transformed to estimate the coefficient on the original scale

${ }^{\mathrm{d}}$ Represents interaction term present in model

'The results are based on a composite measure that includes all forms of workplace health promotion [WHP] (i.e., policy, amenities, injury support, health risk assessment, physical activities, health education, stress/mental health)

noted previously [46] and the distinctions identified by employment band for participating men require further investigation. However, attention to areas such as selfesteem, job security and promotion prospects through stress management programs or primary stress prevention interventions may have been more suited to addressing increased job stress among men.

\section{Limitations}

Repeated-cross sectional designs offer advantages in cost and allow for changes in working population characteristics but they do not allow causal inferences. Neither do they control for baseline differences in exposure to interventions or between individuals, or influences on results due to inter-departmental migration, $[52,53]$. Other research has shown that for large population samples repeated cross-sectional designs can be superior to cohort designs [53]. Linear mixed-modelling analysis also provides robust estimates in the face of modest associations [54]. Further, even though response rates were arguably low, they were typical for organizational surveys [55] and have been addressed here through weighting procedures. We acknowledge it is possible that people with greater stress may have chosen not to respond to the surveys [56, 57]. Our study did not measure societal trends and commonly changing features of public sector workforces may have influenced the observed changes in effort and reward over time. Furthermore, our selfreported measures of exposure may have been too crude. The focus of Healthy@Work was on comprehensive intervention and departmental programs were necessarily different, catering for working circumstances, and employee needs and preferences. This meant that activities also had different levels of content, intensity and levels of delivery and were implemented across a large and diverse working population. Furthermore, participation questions did not ask about the specific dose of activity (i.e., whether the number of times represented a full dose or its portion). Other authors have acknowledged the innate challenges in measuring customized WHP programs [58], and in this setting although the study's design did not capture specific details of availability or participation, it was able to deal with the heterogeneity of comprehensive WHP. We do not know whether the changes in wording of the response period for our exposures affected the results but this approach enabled us to capture the full period of WHP. The selfreported increases in WHP availability appeared to reflect increases in departmental data obtained from the employers' audit processes (Additional file 1: Figure S1) but further investigation is needed to assess selfreported versus actual overlap. More detail on specific 
types of interventions from organizations would have been an advantage. Identification of further exposure effects may require differently timed data collection. Recall bias can also be an issue in self-reported data [59]. Broader conclusions about the generalizability of this study would benefit from follow-up research in other public or private sector workplaces.

\section{Conclusions}

This research provides much-needed evidence of potential benefits obtained from a comprehensive WHP intervention in a naturalistic setting. Interesting gender differences were observed with WHP availability associated with a sense of reward via enhanced self-esteem among women, and WHP participation associated with lower perceived effort in men. Gains associated with comprehensive WHP were modest over time and men in particular may have benefitted from more traditional preventative stress management interventions. These findings appeared generalizable to the general population of public sector workers.

\section{Availability of data and materials}

Data supporting these findings are held by the Menzies Institute for Medical Research and requests for information should be directed to the corresponding author.

\section{Additional files}

Additional file 1: Figure S1. Mean numbers of available Workplace Health Promotion (WHP) initiatives per department reported through Tasmanian Government audits between 2009 and 2012. (PDF 77 kb)

Additional file 2: Figure S2. Question items used in the 2013 Partnering Healthy@Work survey to calculate workplace health promotion exposures for availability and participation. (PDF $171 \mathrm{~kb}$ )

Additional file 3: Figure S3. Flowchart showing sampling and responses to the Partnering Healthy@Work surveys as at November 2014. (PDF 94 kb)

Additional file 4: Table S1. Comparisons of respondents and nonrespondents for Partnering Healthy@Work surveys in 2010 and 2013 by age, tenure, employment condition and employment category, stratified by sex. (PDF $56 \mathrm{~kb}$ )

Additional file 5: Table S2. Cohort characteristics for the 2010 and 2013 Partnering Healthy@Work surveys. (PDF 59 kb)

Additional file 6: Table S3. Ratios of mean reported availability of and participation in Healthy@Work initiatives in 2013 relative to 2010. (PDF 69 kb)

\section{Abbreviations}

WHP: Workplace Health Promotion; ERI: Effort Reward Imbalance; Cl: Confidence Interval.

\section{Competing interests}

The authors have no financial or competing interests in this research.

\section{Authors' contributions}

$\sqcup$ conceptualised the article, participated in data collection, data management and cleaning and wrote the manuscript. AM and AV helped with interpretation of the results and revised the manuscript. PO advised on data analysis and interpretation and revised the manuscript. KS helped with conceptualisation of the paper, interpretation of the results and revised the manuscript. All authors read and approved the final manuscript.

\section{Acknowledgements}

This project was supported by a National Health and Medical Research Council (NHMRC) Partnership Grant (ID 544954) and funding and in-kind support from the Tasmanian Government. LJ was supported by an Australian Post-Graduate Award Scholarship, KS was supported by an Australian Research Council Future Fellowship (FT0991524), and AV by a NHMRC Research Fellowship. The authors are grateful for the support of the Tasmanian Government in this partnership project.

\section{Author details}

${ }^{1}$ Menzies Institute for Medical Research, University of Tasmania, Private Bag 23, Hobart 7000, TAS, Australia. ${ }^{2}$ Tasmanian School of Business and Economics, University of Tasmania, Hobart 7000, TAS, Australia.

Received: 8 September 2015 Accepted: 16 December 2015

Published online: 24 December 2015

\section{References}

1. Darr W, Johns G. Work strain, health, and absenteeism: a meta-analysis. J Occup Health Psychol. 2008;13(4):293-318.

2. Smulders $P$, Nijhuis $F$. The job demands-job control model and absence behaviour: results of a 3-year longitudinal study. Work Stress. 1999;13:115-31.

3. Hoel H, Sparks K, Cooper C. The cost of violence/ stress at work and the benefits of a violence/ stress-free working environment. Geneva: International Labour Organization (ILO); 2001.

4. Stansfeld S, Candy B. Psychosocial work environment and mental health-a meta-analytic review. Scandanavian J Work Environ Health. 2006;32(6):443-62.

5. Kivimaki M, Leino-Arjas P, Luukkonen R, Riihimaki H, Vahtera J, Kirjonen J. Work stress and risk of cardiovascular mortality: prospective cohort study of industrial employees. Br Med J. 2002;325(7369):857.

6. Steptoe A, Kivimaki M. Stress and cardiovascular disease. Nat Rev Cardiol. 2012;9(6):360-70.

7. Siegrist J, Lunau T, Wahrendorf M, Dragano N. Depressive symptoms and psychosocial stress at work among older employees in three continents. Glob Health. 2012;8:27

8. World Health Organization: Workplace health promotion- Benefits. http:// www.who.int/occupational_health/topics/workplace/en/index1.html. Accessed 23 Dec 2015.

9. Van der Klink JJL, Blonk RWB, Schene AH, Van Dijk FJH. The benefits of interventions for work-related stress. Am J Public Health. 2001;91(2):270-6.

10. Richardson KM, Rothstein HR. Effects of occupational stress management intervention programs: a meta-analysis. J Occup Health Psychol. 2008;13(1):69-93.

11. Corbiere M, Shen J, Rouleau M, Dewa CS. A systematic review of preventive interventions regarding mental health issues in organizations. Work (Reading, Mass). 2009;33(1):81-116.

12. Bhui KS, Dinos S, Stansfeld SA, White PD. A synthesis of the evidence for managing stress at work: a review of the reviews reporting on anxiety, depression, and absenteeism. J Environ Public Health. 2012;2012:515874.

13. Stokols D, Pelletier KR, Fielding JE. The ecology of work and health: research and policy directions for the promotion of employee health. Health Educ Q. 1996;23(2):137-58

14. Goetzel RZ, Ozminkowski RJ. The health and cost benefits of work site health-promotion programs. Annu Rev Publ Health. 2008;29:303-23.

15. Baxter S, Sanderson K, Venn A, Blizzard CL, Palmer A. The relationship between return on investment and quality of study methodology in workplace health promotion programs. Am J Health Promot. 2014;28(6):347-63.

16. Pelletier KR. A review and analysis of the clinical and cost-effectiveness studies of comprehensive health promotion and disease management programs at the worksite: update VIII 2008 to 2010. J Occup Environ Med. 2011;53(11):1310-31.

17. Tetrick LE, Winslow CE. Workplace stress management interventions and health promotion. J Organ Psychol Organ Behav. 2015;2:583-603.

18. Parks KM, Steelman LA. Organizational wellness programs: a meta-analysis. J Occup Health Psychol. 2008;13(1):58-68.

19. Aselage J, Eisenberger R. Perceived organizational support and psychological contracts: a theoretical integration. J Organ Behav. 2003;24(5):491-509. 
20. De Groot T, Kiker DS. A meta-analysis of the non-monetary effects of employee health management programs. Hum Resour Manag. 2003;42(1):53-69.

21. Nohammer $\mathrm{E}$, Stummer H, Schuster E. Improving employee well-being through worksite health promotion? The employees' perspective. J Public Health (Oxf). 2010;19(2):121-9.

22. Grossmeier J, Terry PE, Cipriotti A, Burtaine JE. Best practices in evaluating worksite health promotion programs. Art Health Promot. 2010;24(3):TAHP-1.

23. Nohammer $\mathrm{E}$, Schusterschitz C, Stummer H. Employee perceived effects of workplace health promotion. Int J Work Health Mgmt. 2013;6(1):38-53.

24. De Greef M, Van den Broek K. Making the case for workplace health promotion. Analysis of the effects of WHP. 2004.

25. Goldgruber J, Ahrens D. Effectiveness of workplace health promotion and primary prevention interventions: a review. J Public Health (Oxf). 2010;18:75-88.

26. Kivimaki M, Head J, Ferrie JE, Shipley MJ, Brunner E, Vahtera J, et al. Work stress, weight gain and weight loss: evidence for bidirectional effects of job strain on body mass index in the Whitehall II study. Int J Obes (Lond). 2006;30(6):982-7.

27. Albertsen $\mathrm{K}$, Hannerz $\mathrm{H}$, Borg $\mathrm{V}$, Burr $\mathrm{H}$. Work environment and smoking cessation over a five-year period. Scandanavian J Public Health. 2004;32(3): 164-71

28. Kouvonen A, Kivimaki M, Elovainio M, Pentti J, Linna A, Virtanen M, et al. Effort/reward imbalance and sedentary lifestyle: an observational study in a large occupational cohort. Occup Env Med. 2006;63(6):422-7.

29. Stults-Kolehmainen MA, Sinha R. The effects of stress on physical activity and exercise. Sports Med. 2014:44(1):81-121.

30. Chrousos GP. Stress and disorders of the stress system. Nat Rev Endocrinol. 2009:5(7):374-81.

31. Martin A, Sanderson K, Cocker F. Meta-analysis of the effects of health promotion intervention in the workplace on depression and anxiety symptoms. Scandanavian J Work Environ Health. 2009;35(1):7-18.

32. LaMontagne ADKT, Louie AM, Ostry A, Landsbergis PA. A systematic review of the job-stress intervention evaluation literature, 1990-2005. Int J Occup Environ Health. 2007;13(3):268-80.

33. Milat AJ, King L, Bauman AE, Redman S. The concept of scalability: increasing the potential adoption of health promotion interventions into policy and practice. Health Promot Int. 2013;28(3):285-98.

34. Belkic KL, Landsbergis PA, Schnall PL, Baker D. Is job strain a major source of cardiovascular disease risk? Scandanavian J Work Environ Health. 2004;30(2):85-128.

35. Niedhammer I, Sultan-Taieb H, Chastang JF, Vermeylen G, Parent-Thirion A Fractions of cardiovascular diseases and mental disorders attributable to psychosocial work factors in 31 countries in Europe. International archives of occupational and environmental health. 2013;83(4):403-411.

36. Heraclides A, Chandola T, Witte DR, Brunner EJ. Psychosocial stress at work doubles the risk of type 2 diabetes in middle-aged women: evidence from the Whitehall II study. Diabetes Care. 2009:32:2230-5.

37. Siegrist J. A theory of occupational stress. In: Dunham J, editor. Stress in the workplace: past, present and future. London: Whurr Publishers; 2001. p. 52-66.

38. Kivimaki M, Vahtera J, Elovainio M, Virtanen M, Siegrist J. Effort-reward imbalance, procedural injustice and relational injustice as psychosocial predictors of health: complementary or redundant models? Occup Env Med. 2007;64(10):659-65.

39. Wang J, Smailes E, Sareen J, Schmitz N, Fick G, Patten S. Three job-related stress models and depression: A population-based study. Soc Psychiatry Psychiatr Epidemiol. 2012;47(2):185-93.

40. Jarman L, Martin A, Venn A, Otahal P, Taylor R, Teale B, et al. Prevalence and correlates of psychological distress in a large and diverse public sector workforce: baseline results from Partnering Healthy@Work. BMC Pub Health. 2014;14(1):125.

41. Glasgow RE, Vogt TM, Boles SM. Evaluating the public health impact of health promotion interventions: the RE-AIM framework. Am J Public Health. 1999;89(9):1322-7.

42. Siegrist J, Li J, Montano D. Psychometric properties of the Effort-Reward Imbalance Questionnaire. 2014. http://www.uniklinik-duesseldorf.de/ fileadmin/Datenpool/einrichtungen/institut_fuer_medizinische_soziologie_ id54/ERI/PsychometricProperties.pdf. Accessed 23 Dec 2015.

43. Kirkwood BR, Stern JS. Essential medical statistics. 2nd ed. Carlton, Victoria: Blackwell Science Asia Pty Ltd; 2003.

44. Hosmer DW, Lemeshow SL, Sturdivant RX. Applied logistic regression. New York: John Wiley \& Sons; 2013.

45. Little RJA, Rubin DB. Statistical analysis with missing data. 2nd ed. New York: Wiley; 2002
46. Eng A, 't Mannetje A, McLean D, Ellison-Loschmann L, Cheng S, Pearce N. Gender differences in occupational exposure patterns. Occup Env Med. 2011; April 12: oem-2010.

47. Kilpatrick M, Blizzard L, Sanderson K, Teale B, Venn A. Factors Associated With Availability of, and Employee Participation in, Comprehensive Workplace Health Promotion in a Large and Diverse Australian Public Sector Setting: A Cross-Sectional Survey. J Occup Environ Med. 2015;57(11):1197-206.

48. Ko J, Hur S. The impacts of employee benefits, prodecural justice and managerial trustworthiness on work attitudes: Integrated understanding based on Social Exchange Theory. Public Adm Rev. 2014;74(2):176-87.

49. Li J, Yang W, Cho SI. Gender differences in job strain, effort-reward imbalance, and health functioning among Chinese physicians. Soc Sci Med. 2006;62(5):1066-77.

50. Benach J, Muntaner C. Precarious employment and health: developing a research agenda. J Epi Comm Health. 2007;61(4):276-7.

51. Benach J, Vives A, Amable M, Vanroelen C, Tarafa G, Muntaner C. Precarious employment: understanding an emerging social determinant of health. Annu Rev Publ Health. 2014;35:229-53.

52. Atienza AA, King AC. Community-based health intervention trials: an overview of methodological issues. Epi Rev. 2002;24(1):72-9.

53. Diehr P, Martin D, Koepsell T, Cheadle A, Psaty B. Optimal survey design for community intervention evaluations: Cohort or cross-sectional? J Clin Epidemiol. 1995:48(12):1461-72.

54. Diez-Roux A. Multilevel analysis in public health research. Annu Rev Publ Health. 2000;21:171-92.

55. Hilton MF, Whiteford HA, Sheridan JS, Cleary CM, Chant DC, Wang PS, et al. The prevalence of psychological distress in employees and associated occupational risk factors. J Occup Environ Med. 2008;50(7):746-57.

56. Knudsen AK, Hotopf M, Skogen JC, Overland S, Mykletun A. The health status of nonparticipants in a population-based health study: the Hordaland Health Study. Am J Epidemiol. 2010;172(11):1306-14.

57. Chandola T, Britton A, Brunner E, Hemingway H, Malik M, Kumari M, et al. Work stress and coronary heart disease: what are the mechanisms? Eur Heart J. 2008;29(5):640-8.

58. Seaverson EL, Grossmeier J, Miller TM, Anderson DR. The role of incentive design, incentive value, communications strategy, and worksite culture on Health Risk Assessment participation. Health Promot Int. 2009;23(5):343-52 59. Delgado-Rodriguez M, Llorca J. Bias. J Epi Comm Health. 2004;58(8):635-41.

\section{Submit your next manuscript to BioMed Central and we will help you at every step:}

- We accept pre-submission inquiries

- Our selector tool helps you to find the most relevant journal

- We provide round the clock customer support

- Convenient online submission

- Thorough peer review

- Inclusion in PubMed and all major indexing services

- Maximum visibility for your research

Submit your manuscript at www.biomedcentral.com/submit
C Biomed Central 